\title{
The dynamical impact of Rossby wave breaking upon UK PM10 concentration
}

\author{
Christopher P. Webber, Helen F. Dacre, William J. Collins, and Giacomo Masato \\ Department of Meteorology, University of Reading, Berkshire, RG6 6AX, UK \\ Correspondence to: Christopher P. Webber (c.p.webber@pgr.reading.ac.uk)
}

Received: 1 July 2016 - Published in Atmos. Chem. Phys. Discuss.: 28 July 2016

Revised: 30 November 2016 - Accepted: 15 December 2016 - Published: 20 January 2017

\begin{abstract}
Coarse particulate matter $\left(\mathrm{PM}_{10}\right)$ has long been understood to be hazardous to human health, with mortality rates increasing as a result of raised ground level concentrations. We explore the influence of synoptic-scale meteorology on daily mean observed $\mathrm{PM}_{10}$ concentration ([PM $\left.\mathrm{PM}_{10}\right]$ ) using Rossby wave breaking (RWB). Meteorological reanalysis data for the winter months (DJF) between January 1999 and December 2008 and observed $\mathrm{PM}_{10}$ data for three urban background UK (Midland) sites were analysed. Three RWB diagnostics were used to identify RWB that had significant influence on UK Midland $\mathrm{PM}_{10}$. RWB events were classified according to whether the RWB was cyclonic or anticyclonic in its direction of breaking and whether the RWB event was influenced more by poleward or equatorial air masses.

We find that there is a strong link between RWB events and UK [ $\left.\mathrm{PM}_{10}\right]$. Significant increases $(p<0.01)$ in UK $\left[\mathrm{PM}_{10}\right]$ were seen 1 day following RWB occurring in spatially constrained northeast Atlantic-European regions. Analysis into episodic $\mathrm{PM}_{10}$ exceedance events shows increased probability of $\left[\mathrm{PM}_{10}\right]$ exceedance associated with all RWB subsets. The greatest probability of exceeding the UK $\left[\mathrm{PM}_{10}\right]$ threshold was associated with cyclonic RWB preceded by anticyclonic RWB forming an $\Omega$ block synoptic pattern. This mechanism suggests an easterly advection of European $\mathrm{PM}_{10}$ followed by prolonged stagnant conditions within the UK and led to an almost threefold increase in the probability of the UK Midlands exceeding a hazardous $\left[\mathrm{PM}_{10}\right]$ threshold (0.383), when compared to days where no RWB was detected (0.129).
\end{abstract}

\section{Introduction}

The influence of large-scale flow patterns upon pollutant concentrations within the UK is often overlooked in relation to the contribution of local sources, sinks and smaller-scale boundary layer transport processes. However some source receptor (Charron et al., 2013) and source attribution (Yin and Harrison, 2008) studies have shown the influence that external (continental European) sources have upon pollutant levels within the UK. Both studies highlight the strong influence of large-scale advected inorganic species on UK particulate matter $(\mathrm{PM})$ with an aerodynamic diameter $\leq 10 \mu \mathrm{m}\left(\mathrm{PM}_{10}\right)$. The aim of this study is to quantify the relationship between large-scale atmospheric flow patterns and $\mathrm{UK} \mathrm{PM}_{10}$ concentration $\left(\left[\mathrm{PM}_{10}\right]\right)$ and to understand the mechanisms driving this relationship.

PM was chosen as the subject of analysis due to its detrimental impacts upon human health (Kappos et al., 2004). The health impacts of PM depend greatly on its size and composition, with finer particles able to travel further down the human respiratory tract, consequently increasing its anthropogenic toxicity. Throughout the period of this study, the monitoring of fine PM $\left(\mathrm{PM}_{2.5}\right)$ was spatially poor, and so $\mathrm{PM}_{10}$ was analysed.

Previous research has shown the dominant synoptic regimes influencing the UK, which can be generally described by zonal flow and blocked flow (Pope et al., 2015 and McGregor and Bamzelis, 1999). McGregor and Bamzelis (1999) highlighted that UK $\left[\mathrm{PM}_{10}\right]$ was significantly reduced by the presence of zonal flow entering the UK, while blocked regimes influenced an increase in UK [ $\left.\mathrm{PM}_{10}\right]$. Zonal- and blocked-flow patterns are largely determined by the absence or occurrence of Rossby wave breaking (RWB) 
within the northeast Atlantic-European region (Woollings et al., 2008).

Synoptic-scale baroclinic eddies lead to wave-like distortions of the subtropical jet and to wave-breaking regions on the poleward and equatorward sides of the jet (known as RWB) (Haynes, 2003). RWB is the large-scale meridional overturning on a longitude-latitude quasi-horizontal plane of air masses in the upper troposphere, caused by meridional zonal shear determined by the relative position of the mid-latitude eddy-driven jet (EDJ). RWB leads to blocked flow within the northeast Atlantic-European region through the generation of a climatologically anomalous high-pressure system over western Europe. High pressure is directly associated with the elevation of $\left[\mathrm{PM}_{10}\right]$. through the suppression of vertical mixing-out of the boundary layer. This high-pressure anomaly can also influence the UK through the generation of weak winds or easterlies over the region. We hypothesise therefore that the generation of anomalous easterlies into the UK will facilitate the advection of $\mathrm{PM}_{10}$ from the European continent and consequently raise UK $\left[\mathrm{PM}_{10}\right]$. In addition to enhancing European PM advection into the UK, RWB is also shown to disrupt the mid-latitude EDJ and subsequent northeast Atlantic storm track. Associated with the storm track are loss mechanisms effective in removing ambient PM. Increased precipitation is the greatest PM sink associated with enhanced storm activity, while the introduction of a cleaner westerly maritime air mass acts to lower background UK $\left[\mathrm{PM}_{10}\right]$ (McGregor, 1999). Furthermore, enhanced storm activity is associated with elevated surface wind velocity (horizontal and vertical), which enables the transport of surface $\mathrm{PM}_{10}$ away from the surface source region. This advection of $\mathrm{PM}_{10}$ from the source region results in a reduction of surface $\left[\mathrm{PM}_{10}\right]$, as the pollutant becomes more disperse.

In this study RWB is diagnosed on the tropopause, which can be identified dynamically using the potential vorticity $(\mathrm{PV})=2 \mathrm{PVU}$ surface (where $1 \mathrm{PVU}=1 \times 10^{-6} \mathrm{~m}^{2} \mathrm{~s}^{-1} \mathrm{~K} \mathrm{~kg}^{-1}$ ). The diagnostic used to diagnose RWB is potential temperature on the 2-PVU $(\theta$ 2 PVU) surface. RWB is seen as the meridional overturning of the mean $\theta-2 \mathrm{PVU}$ gradient, which decreases (increases) towards the poles (Equator). $\theta$ is materially conserved following frictionless, adiabatic (isentropic) flow, and to a good approximation the extratropical atmosphere behaves as an adiabatic and frictionless fluid (Hoskins, 1997). $\theta$ has been used on numerous occasions to identify extratropical blocking resultant from RWB (Pelly and Hoskins, 2003; Shutts, 1983; Tyrlis and Hoskins, 2008). The significance of the 2-PVU isertelic surface is that, at the tropopause, the isentropic gradients are vertically concentrated and that, with one surface, upper-level synoptic features can be illustrated (Morgan and Nielsen-Gammon, 1998).

The daily mean, mean sea level pressure (MSLP) response to RWB is a MSLP dipole formed of an anomalous high (low)-pressure lobe to the north (south) of the centre of overturning (Masato et al., 2013 - hereafter M13). A region char- acterised by anomalously low PV, i.e. cyclonic motion, is associated with upper-tropospheric divergence and subsequent convergence in the lower troposphere. Such a pattern is associated with anomalously low MSLP. The opposite signal can be seen for anomalously high PV or anticyclonic motion. The pressure dipole results from the meridional advection of upper-level air masses with anomalous PV characteristics. Equatorward air masses have lower PV due to a lower planetary vorticity component, while poleward air masses experience high planetary vorticity and subsequently high PV. When these air masses are meridionally overturned such as in RWB, anomalously high (low) PV is advected south (north), resulting in cyclonic (anticyclonic) tendencies.

We hypothesise that RWB will impact UK [ $\mathrm{PM}_{10}$ ] through the displacement of the EDJ and removal of the primary $\mathrm{PM}_{10}$ loss mechanisms. Following this, if RWB is to become influential upon raising $\left[\mathrm{PM}_{10}\right]$ above a background concentration, an element of persistence is required (Cattiaux et al., 2010). If a persistent atmospheric block is produced, this will facilitate the accumulation of either local or advected $\mathrm{PM}_{10}$. Furthermore, easterlies associated with RWB may advect continental PM into the UK and subsequently increase local $\left[\mathrm{PM}_{10}\right]$.

\section{Methodology}

Within this study, data were analysed for the winter months (DJF) as it has been previously found that RWB is the primary mechanism for persistent high pressure over the UK region, during the winter (Pelly and Hoskins, 2003). The extent of all data used within this paper is January 1999-February 2008 (DJF).

\subsection{Meteorological large-scale flow diagnostics}

M13 developed a 2-D blocking index (BI) which measured the meridional extent to which the constant $\theta$-2 PVU contour has overturned (Eq. 3). A positive BI value indicates overturning of the $\theta-2 \mathrm{PVU}$ contour, representing blocked flow, while negative BI values represent zonal flow. Equations (1) and (2) represent mean $\theta(\bar{\theta})$ at $15^{\circ}$ latitude $(\phi)$ to the north/south $(\mathrm{n} / \mathrm{s})$ of the grid point of interest $\left(\phi_{0}\right)$ respectively for every grid point, with $\mathrm{i}$ and $\mathrm{j}$ representing longitudinal and latitudinal coordinates, and $\Delta \phi$ is given in kilometres.

$$
\begin{aligned}
& \bar{\theta}_{i, j, \mathrm{t}}^{n}=\frac{2}{\Delta \phi} \int_{\phi_{0}}^{\phi_{0}+\Delta \phi / 2} \theta_{i, j, \mathrm{t}} \mathrm{d} \phi \\
& \bar{\theta}_{i, j, \mathrm{t}}^{s}=\frac{2}{\Delta \phi} \int_{\phi_{0}-\Delta \phi / 2}^{\phi_{0}} \theta_{i, j, \mathrm{t}} \mathrm{d} \phi
\end{aligned}
$$


$\mathrm{BI}_{i, j, \mathrm{t}}=\bar{\theta}_{i, j, \mathrm{t}}^{n}-\bar{\theta}_{i, j, \mathrm{t}}^{s}$

A second diagnostic, the direction-of-blocking index (DB index), is used to determine the zonal gradient of the $\theta$ $2 \mathrm{PVU}$ surface. The metric diagnoses whether an overturning occurs in either a cyclonic (CRWB) or anticyclonic (ACRWB) direction. Variations of this diagnostic have been used within multiple studies (Weijenborg et al., 2012; M13; and Pelly and Hoskins, 2003), but the 2-D DB index described in M13 is used within this study. The DB index is calculated using Eq. (5) and is a measure of the horizontal gradient of $\theta$ centred on the grid point of interest. The equation describes $\bar{\theta}$ to the east of the grid point of interest subtracted from $\bar{\theta}$ to the west of the grid point. A positive DB index value indicates that the overturning will rotate with anticyclonic motion, while for negative values a cyclonic motion is diagnosed. Weijenborg et al. (2012) showed that CRWB and ACRWB occur climatologically in different regions. It was shown by Weijenborg et al. (2012) that the meridional zonal shear, determined by the position of the EDJ, generates cyclonic (anticyclonic) motion to its north (south), resulting in CRWB (ACRWB) occurring.

$\bar{\theta}_{i, j, \mathrm{t}}=\frac{\bar{\theta}_{i, j, \mathrm{t}}^{n}+\bar{\theta}_{i, j, \mathrm{t}}^{s}}{2}$

$\mathrm{DB}_{i, j}=\bar{\theta}_{i-1, j, \mathrm{t}}-\bar{\theta}_{i+1, j, \mathrm{t}}$

The diagnostic detailed in Eq. (6) is the relative intensity of air masses index (RI index), which compares the relative quantities of warm equatorial air to cold poleward air influencing a RWB event. This metric measures the $\bar{\theta}_{i, j \mathrm{t}}$ anomaly at a given time $(t)$ from the 44-year climatological ERAInterim winter (DJF) value for that grid point $\left(\theta_{i, j}^{*}\right)$. If this value is positive (negative), it indicates that the overturning event is majority warm (cold) influenced. This metric helps to determine the strength of the low (high)-PV lobes to the south (north) of a RWB event. The strength of the PV lobes will directly influence the strength of the associated pressure anomalies within the associated MSLP dipole.

For both the DB and RI indices, any magnitude within the range of $(-0.2 \mathrm{~K} \leq \times \leq 0.2 \mathrm{~K})$ is determined unclassified as described in M13. All blocking metrics used within this study were generated using ECMWF ERA-Interim reanalysis data (Dee et al., 2011). The data have been temporally filtered as $24 \mathrm{~h}$ mean values, generating daily resolved large-scale flow diagnostics. As in M13 a $15^{\circ}$ longitudinal running-mean filter has been applied to the calculated fields for $\bar{\theta}_{i, j, \mathrm{t}}^{n}$ and $\bar{\theta}_{i, j, \mathrm{t}}^{s}$. The longitudinal filter removes the influence of smallscale transient features on the calculation of the DB and RI indices.

$\mathrm{RI}_{i, j}=\bar{\theta}_{i, j, \mathrm{t}}-\theta_{i, j}^{*}$

\section{$2.2 \quad \mathrm{PM}_{10}$ data}

$\mathrm{PM}_{10}$ data from three UK Midland $\mathrm{PM}_{10}$ monitoring sites - Birmingham Central, Leicester Central and Leamington Spa - were used for winter months (DJF) between January 1999 and February 2008 (DEFRA, 2014a). The three sites used are all classified by DEFRA (DEFRA, 2014b) as urban background sites, each representative of its urban environment, away from direct anthropogenic $\mathrm{PM}_{10}$ sources (DEFRA, 2014b). The primary benefit of using such a site is that the majority of the UK's population live within urban areas. To best represent the UK, a sampling region was selected within the centre of the UK, to account for influences from all directions. The urban background $\mathrm{PM}_{10}$ sites chosen for this study's analysis are subject to occasional emissions from dominant local $\mathrm{PM}_{10}$ sources, which urban background sites are located to avoid (DEFRA, 2014b). Such interferences can be identified as spikes on a $\mathrm{PM}_{10}$ time series. Inconsistent, localised $\left[\mathrm{PM}_{10}\right]$ spikes were identified for each site and removed when the daily mean $\left[\mathrm{PM}_{10}\right]$ tendency $\left(\left[\mathrm{PM}_{10}\right]_{t}-\left[\mathrm{PM}_{10}\right]_{t-1}\right)$ at two sites contrasted that of the third site. All tendency differences that lay within the top $10 \%$ of tendency differences from the entire dataset were removed as locally influenced spikes. The sites used formed a tri-site super site, and the daily $\left[\mathrm{PM}_{10}\right]$ from each site was averaged to form one representative running mean. In a situation where a site has data removed due to irregularities in tri-site comparisons, $\mathrm{PM}_{10}$ from the remaining two sites was used. Additional analysis (shown in the Supplement) has found that the data validation step of removing $\mathrm{PM}_{10}$ spikes has improved the Pearson's correlation coefficient between each original $\mathrm{PM}_{10}$ dataset. In the original $\left[\mathrm{PM}_{10}\right]$ datasets, the correlation coefficients between the three observational $\mathrm{PM}_{10}$ sites varied between 0.73 and 0.86 . Following the data validation step, the correlation coefficients varied between 0.86 and 0.87. $\left[\mathrm{PM}_{10}\right]$ datasets inherently have log-normal distributions; therefore all $\left[\mathrm{PM}_{10}\right]$ values quoted within this study will be of the form $\ln \left[\mathrm{PM}_{10}\right]$ to ensure that the tri-site dataset has a normal Gaussian distribution.

In this study $\left[\mathrm{PM}_{10}\right]$ exceedances are defined using a threshold based on results from the Air Pollution and Health: A European Approach 2 (APHEA2) epidemiological cohort study. The APHEA2 project highlighted that detrimental anthropogenic impacts were shown to be significant for $\left[\mathrm{PM}_{10}\right]$ that exceeded a site's $\overline{\left[\mathrm{PM}_{10}\right]}$ by $10 \mu \mathrm{g} \mathrm{m}^{-3}$ (Katsouyanni et al., 2001). For $\mathrm{PM}_{2.5}$ levels the same conclusions were reached (Beelen et al., 2014; Gehring et al., 2013), highlighting the importance of long-distance advected PM sources, most likely fine PM, on UK health. It is worth noting that, while significant increases in detrimental health impacts have been shown for $\left[\mathrm{PM}_{10}\right]$ above the threshold used in this study, detrimental health effects have been shown to occur at lower ambient $\left[\mathrm{PM}_{10}\right]$ (Brook et al., 2010). The $\overline{\left[\mathrm{PM}_{10}\right]}$ from the three sites are as follows: Birmingham Central, $20.26 \mu \mathrm{g} \mathrm{m}^{-3}\left(\ln \left[\mathrm{PM}_{10}\right]=3.01\right)$; Le- 


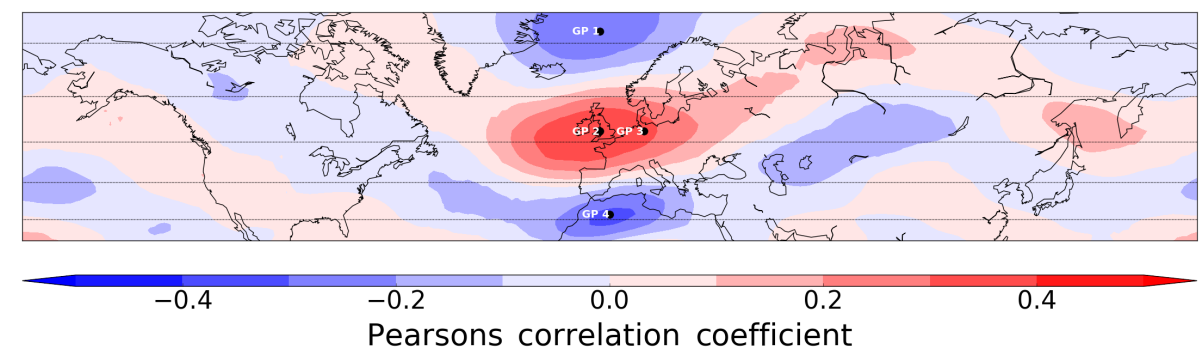

Figure 1. Pearson's correlation coefficient between blocking index magnitude $(\mathrm{K})$ and $\mathrm{UK}\left[\mathrm{PM}_{10}\right]\left(\mu \mathrm{g}^{-3}\right)$ in the UK Midlands region. All data were taken for the winter months (DJF) between January 1999 and December 2008. PM 10 data following a positive or negative BI value were lagged by 1 or 0 days respectively. Grid points selected for further analysis are labelled GP 1 to 4 .

icester Central, $18.62 \mu \mathrm{g} \mathrm{m}^{-3}\left(\ln \left[\mathrm{PM}_{10}\right]=2.92\right)$; and Leamington Spa, $18.63 \mu \mathrm{g} \mathrm{m}^{-3}\left(\ln \left[\mathrm{PM}_{10}\right]=2.93\right)$. The tri-site $\overline{\left[\mathrm{PM}_{10}\right]}$ is $19.72 \mu \mathrm{g} \mathrm{m}^{-3}$ or $\ln \left[\mathrm{PM}_{10}\right]=2.98$. Therefore we use a threshold for daily mean $\left[\mathrm{PM}_{10}\right]$ of $29.72 \mu \mathrm{g} \mathrm{m}^{-3}$ or $\ln \left[\mathrm{PM}_{10}\right]=3.39$ to define an exceedance. For comparison, the European legal daily threshold is currently set at $50 \mu \mathrm{g} \mathrm{m}^{-3}$ and must not be exceeded more than 35 times a year (Council of the European Union, 2008).

The concept of a temporal lag between BI and UK $\left[\mathrm{PM}_{10}\right]$ is explored during the analysis. The greatest UK $\left[\mathrm{PM}_{10}\right]$ is found when using a 1-day lag following $\mathrm{BI}>0 \mathrm{~K}$. The lag accounted for the time taken for European $\mathrm{PM}_{10}$ to advect into the UK and for the UK to subsequently be exposed to a new air mass. In events where RWB was not diagnosed $(\mathrm{BI}<0 \mathrm{~K})$, it was found that a 0 -day lag provided the strongest relationships between RWB and [PM $\left.\mathrm{PM}_{10}\right]$. Negative BI values are associated with westerlies entering the UK, providing the most efficient $\left[\mathrm{PM}_{10}\right]$ removal processes. These removal processes reduce surface $\left[\mathrm{PM}_{10}\right]$ on timescales of less than a day, and hence there is a lag of 0 days between negative $\mathrm{BI}$ values and resultant UK $\left[\mathrm{PM}_{10}\right]$. Therefore in Sect. 3.1 and 3.2, when a day is not indicating RWB (BI >0 K), no temporal lag was applied.

\section{Results}

Section 3 presents the main results from this study. Section 3.1 begins by analysing the relationship between BI and UK Midlands $\left[\mathrm{PM}_{10}\right]$. Section 3.2 presents regions where RWB occurrences result in significantly elevated UK $\left[\mathrm{PM}_{10}\right]$. This analysis is undertaken for four RWB subsets: warm anticyclonic, cold anticyclonic, warm cyclonic and cold cyclonic RWB. Section 3.3 analyses the MSLP response to both ACRWB and CRWB. The most important result from this study is presented in Sect. 3.4 and refers to the probability that days on which RWB occurs lead to hazardous $\mathrm{PM}_{10}$ threshold exceedances. A RWB subset that results in the greatest probability of exceeding a hazardous UK $\left[\mathrm{PM}_{10}\right]$ threshold is examined in more detail in Sect. 3.5. The mechanism dictating the occurrence of northeast Atlantic-
European CRWB is presented in Fig. 6 and discussed from Sect. 3.5 onwards.

\subsection{2-D spatial relationship between $\mathrm{BI}$ and $\mathrm{UK} \mathrm{PM}_{10}$}

Figure 1 illustrates the relationship between BI magnitude and UK $\left[\mathrm{PM}_{10}\right]$. At each grid point the Pearson correlation coefficient between $\mathrm{BI}$ at that grid point and $\mathrm{PM}_{10}$ at the central UK Midlands site is shown. A region of positive correlation is found centred over the English Channel, and two regions of negative correlation are found north and south of this positive-correlation region. The region of positive correlation is a result of one of three potential mechanisms: (i) RWB increases the number of high-[ $\left[\mathrm{PM}_{10}\right]$ events, (ii) RWB reduces the number of low-[ $\left[\mathrm{PM}_{10}\right]$ events or (iii) a combination of (i) and (ii). By analysing the BI-[PM $\left.\mathrm{PM}_{10}\right]$ relationship at individual grid points within the region of positive and negative correlation, we can determine which of these mechanisms dominates the relationship.

In order to understand the patterns in Fig. 1, four grid points were selected and labelled GP 1 to 4 in Fig. 1. GPs 1 and 4 were selected because they lie within two separate regions of negative correlation, while GPs 2 and 3 both lie within the region of positive correlation. Figure $2 b$ and $c$ highlights the positive relationships between the BI magnitude and UK $\left[\mathrm{PM}_{10}\right]$ at GPs 2 and 3, with correlation coefficients (CCs) of 0.43 and 0.35 respectively. The positive relationship is a result of contributions from negative and positive BI values, shown as blue and red in Fig. 2 respectively. In both cases, the negative BI values represent a similar positive correlation to that of the overall trend, $\mathrm{CC}=0.36$ and 0.25 for GPs 2 and 3 respectively. Based upon results of a one-tailed $t$ test, all negative and total correlation coefficients are significantly different from zero $(p=0.01)$, with only the positive correlation coefficient for GP 3 showing a significant correlation $(p=0.002)$. For GP 2 and GP 3, variability in the negative BI values dominates the relationship between $\mathrm{BI}$ and $\left[\mathrm{PM}_{10}\right]$. Subsequently, with negative BI values corresponding to zonal flow, the variability in the magnitude of the zonal flow over these regions explains much of the variability in UK Midland $\left[\mathrm{PM}_{10}\right]$. GPs 1 and 4 exhibit 
(a)

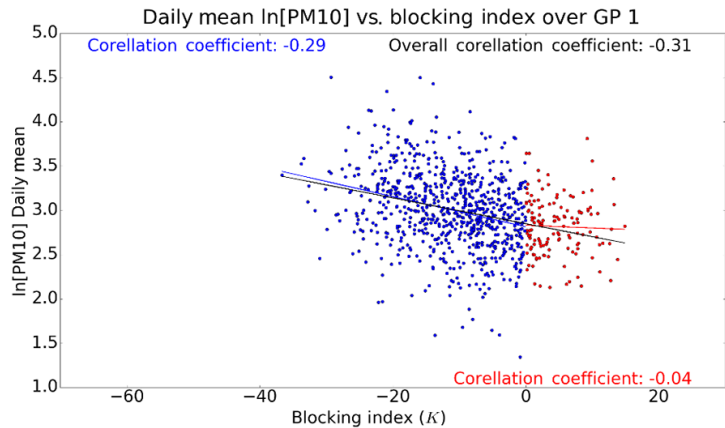

(c)

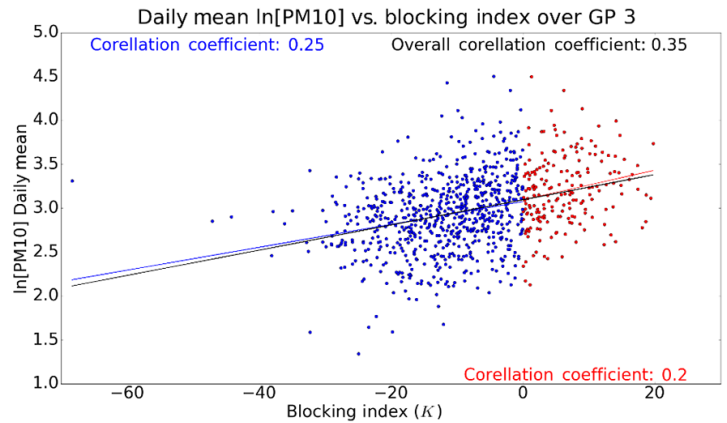

(b)

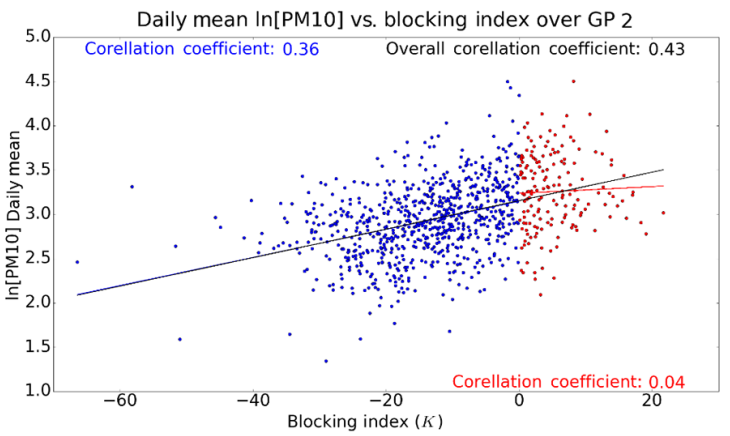

(d)

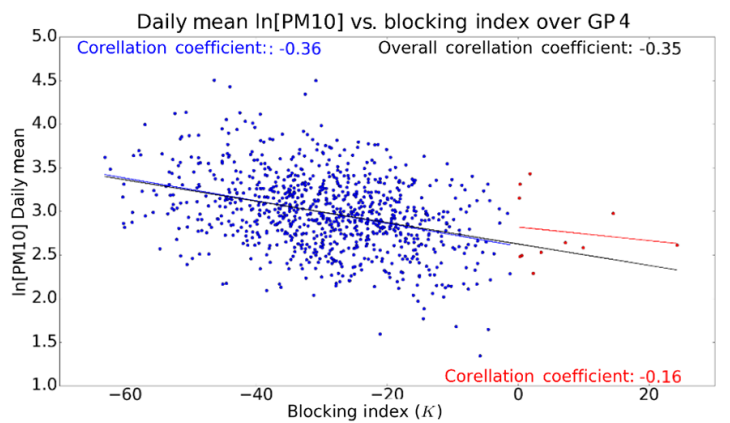

Figure 2. Scatter plots illustrating the relationship between blocking index magnitude $(\mathrm{BI})(\mathrm{K})$ and $\mathrm{UK}\left[\mathrm{PM}_{10}\right]\left(\mu \mathrm{g}^{-3}\right)$ for four regions, labelled GP 1, 2, 3 and 4 in Fig. 1 (labelled (a), (b), (c) and (d) in Fig. 2). The blue and red colour corresponds to negative and positive BI values respectively, and the fitted trends are linear least-squares trends. Data were obtained for DJF January 1999-December 2008, and $\left[\mathrm{PM}_{10}\right]$ lagged by 1 and 0 days for positive and negative $\mathrm{BI}$ values respectively.

a negative correlation between $\mathrm{BI}$ and $\mathrm{PM}_{10}(\mathrm{CC}=-0.31$ and -0.35 respectively). The negative $\mathrm{BI}$ values in both cases $(\mathrm{CC}=-0.29$ and -0.36 respectively) display nearly identical relationships with UK $\left[\mathrm{PM}_{10}\right]$ to the overall trend. Despite the relationships seen between BI and UK Midlands $\left[\mathrm{PM}_{10}\right]$ being dominated by negative $\mathrm{BI}$ values at all four selected regions, positive $\mathrm{BI}$ values are associated with elevated $\left[\mathrm{PM}_{10}\right]$ at GP 2 and 3. At GP 2 and 3, the increased [PM$\left.{ }_{10}\right]$ associated with positive BI values indicates that RWB increases the number of high- $\left[\mathrm{PM}_{10}\right]$ events, despite the magnitude of positive BI values not strongly correlating with UK Midlands $\left[\mathrm{PM}_{10}\right]$. Figure $2 \mathrm{~b}$ and $\mathrm{c}$ are influenced by very low $\mathrm{BI}$ values, which appear as outliers in the general distribution. It was seen that, by removing BI values $<-30 \mathrm{~K} \mathrm{~km}^{-1}$, there was very little impact on the overall $\mathrm{CC}$ values obtained from Fig. 2b and c. In Fig. 2b and c the Pearson's correlation coefficient increases from 0.43 to 0.44 and from 0.35 to 0.37 respectively, following the removal of the outliers.

With the relationship between enhanced zonal flow and low $\left[\mathrm{PM}_{10}\right]$ dominating the correlations seen in Fig. 2, it can be presumed that the main influence upon this relationship is the EDJ. Figure 1 illustrates a zonal wave pattern of positive correlation between $\mathrm{BI}$ and $\mathrm{UK}\left[\mathrm{PM}_{10}\right]$ that is synonymous with the meandering winter EDJ location. Within this region lie the strongest wind speeds, which are coincident with strong surface wind speeds over the UK, during a zonal synoptic regime. As the EDJ is the dominant feature in the positive correlation between $\mathrm{BI}$ and $\mathrm{UK}\left[\mathrm{PM}_{10}\right]$, a positive correlation represents an outline of the meandering winter EDJ location results.

\subsection{Relationships between Rossby wave breaking subsets and $\mathrm{UK}_{\mathrm{PM}} \mathrm{PM}_{10}$}

Despite the lack of positive correlation between positive BI values and $\left[\mathrm{PM}_{10}\right]$, positive $\mathrm{BI}$ values are associated with above-average UK $\left[\mathrm{PM}_{10}\right]$. In this section we investigate how RWB leads to raised UK $\left[\mathrm{PM}_{10}\right]$. Two criteria, described by Masato et al. (2012) (hereafter M12) and M13, are used in this study: the DB and RI indices. Table 1 shows thresholds used to define four RWB types analysed in this study.

For each day on which RWB occurs at a given grid point, the type of RWB is determined from the criteria in Table 1, and the corresponding $\ln \left(\left[\mathrm{PM}_{10}\right]\right), 1$ day after, is stored for that RWB subset. Following this, UK $\ln \left(\overline{\left[\mathrm{PM}_{10}\right]}\right)$ for each RWB subset is calculated for every grid point. Figure 3 illustrates UK $\ln \left(\overline{\left[\mathrm{PM}_{10}\right]}\right)$ for the four RWB subsets listed in Table 1. Included in Fig. 3 are contoured regions representing grid points where subset $\ln \left(\overline{\left[\mathrm{PM}_{10}\right]}\right)$ is significantly greater than the $\ln \left(\overline{\left[\mathrm{PM}_{10}\right]}\right)$ for the entire dataset (described by Eq. 7), otherwise termed "regions of influence". For each grid point, the standard error of the subset $\ln \left(\overline{\left[\mathrm{PM}_{10}\right]}\right)$ was calculated and multiplied by 1.96 to represent a onetailed $99 \%$ confidence interval. Equation (8) describes regions where the subset $\ln \left(\overline{\left[\mathrm{PM}_{10}\right]}\right)$ is significantly less than 
Table 1. Defining Rossby wave breaking (RWB) types using thresholds of the direction of blocking (DB) and relative influence of air masses (RI) indices. Any RWB with DB or RI values of $-0.2 \leq \times \leq 0.2 \mathrm{~K}$ is determined as unclassified following Masato et al. (2012).

\begin{tabular}{lrrr}
\hline $\begin{array}{l}\text { Rossby wave } \\
\text { Breaking type }\end{array}$ & $\begin{array}{r}\text { Blocking index (BI) } \\
\mathrm{K}\end{array}$ & $\begin{array}{r}\text { Direction of blocking } \\
\text { index (DB) K }\end{array}$ & $\begin{array}{r}\text { Relative influence of air } \\
\text { masses index (RI) K }\end{array}$ \\
\hline Warm anticyclonic & $>0$ & $>0.2$ & $>0.2$ \\
Cold anticyclonic & $>0$ & $>0.2$ & $<-0.2$ \\
Warm cyclonic & $>0$ & $<-0.2$ & $>0.2$ \\
Cold cyclonic & $>0$ & $<-0.2$ & $<-0.2$ \\
\hline
\end{tabular}

(a)

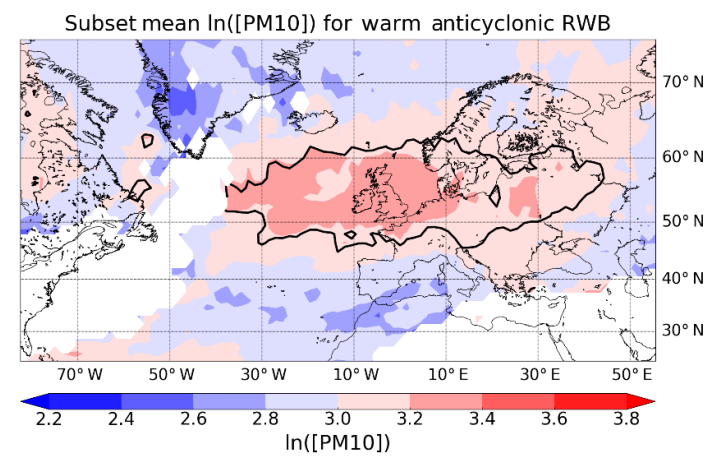

(c)

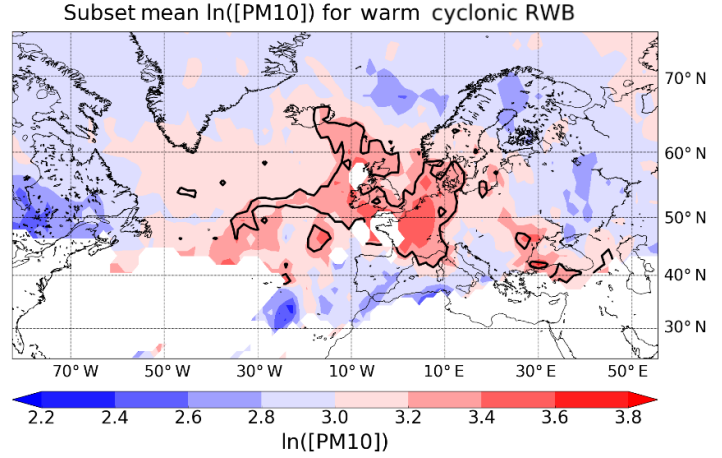

(b)

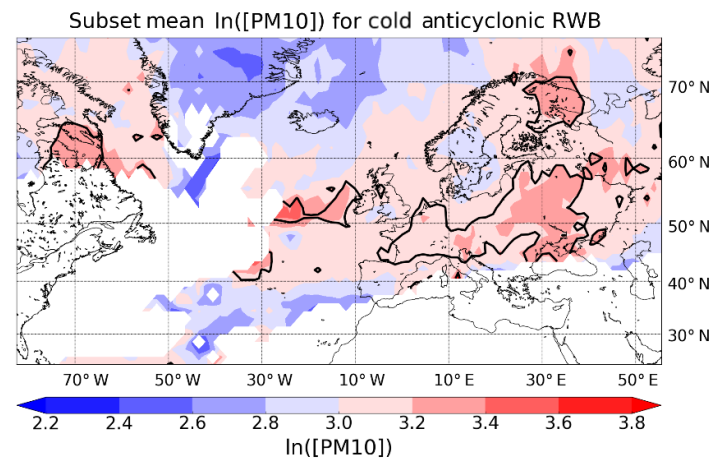

Subset mean $\ln ([\mathrm{PM} 10])$ for cold cyclonic RWB

(d)

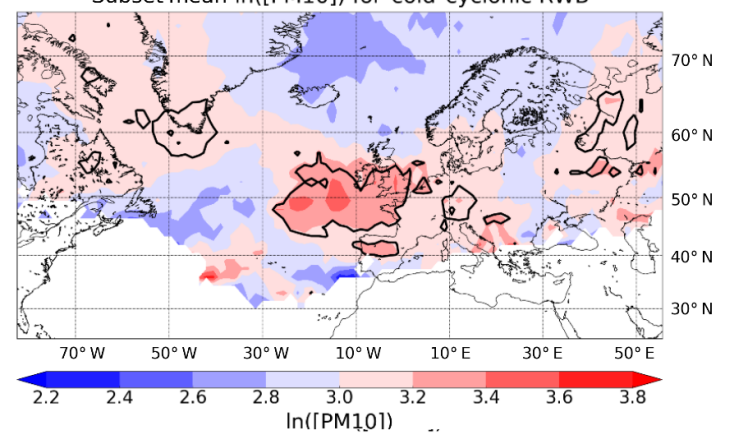

Figure 3. One-day lagged UK Midlands mean $\left[\mathrm{PM}_{10}\right]$ subset $\left({\overline{\left[\mathrm{PM}_{10}\right]}}_{\text {Subset }}\right)$ for each point within a gridded region for (a) warm anticyclonic, (b) cold anticyclonic, (c) warm cyclonic and (d) cold cyclonic Rossby wave breaking events. Solid (dashed) contours constrain regions where mean $\ln \left[\mathrm{PM}_{10}\right]$ for each grid point is significantly greater (lower) than the entire dataset $\ln \left[\mathrm{PM}_{10}\right]$ mean $(p<0.01)$. White grid points represent points where RWB has occurred on less than two occasions throughout DJF January 1999-December 2008. Dataset mean $\left[\mathrm{PM}_{10}\right]=21.69 \mu \mathrm{g} \mathrm{m}^{-3}$.

the dataset $\ln \left(\overline{\left[\mathrm{PM}_{10}\right]}\right)$ and illustrated by a dashed black contour in Fig. 3. Within these equations $\sigma$ represents standard deviation and $N$ represents the number of samples within the subset or dataset.

$$
\begin{aligned}
& {\overline{\left[\mathrm{PM}_{10}\right]}}_{\mathrm{Sub}}-{\overline{\left[\mathrm{PM}_{10}\right]_{\mathrm{All}}}}_{\mathrm{A}}>1.96 \sqrt{\left(\frac{\sigma_{\text {Sub }}^{2}}{N_{\text {Sub }}}+\frac{\sigma_{\mathrm{All}}^{2}}{N_{\mathrm{All}}}\right)} \\
& {\overline{\left[\mathrm{PM}_{10}\right]}}_{\mathrm{All}}-{\overline{\left[\mathrm{PM}_{10}\right]}}_{\mathrm{Sub}}>1.96 \sqrt{\left(\frac{\sigma_{\text {Sub }}^{2}}{N_{\text {Sub }}}+\frac{\sigma_{\text {All }}^{2}}{N_{\text {All }}}\right)}
\end{aligned}
$$

Contoured regions of influence were found outside of the domain shown in Fig. 3, but these incorporated few RWB events randomly coinciding with RWB events within the do- main. To focus on the regions that are shown to be influential to UK $\left[\mathrm{PM}_{10}\right]$, a longitudinal mask has been applied so that only longitudes east of $277.5^{\circ} \mathrm{E}$ and west of $77^{\circ} \mathrm{E}$ are included in this analysis.

First of note from Fig. 3 are the similarities in location between the cyclonic and anticyclonic RWB regions of influence, with influential regions most prevalent within the northeast Atlantic-European region. Climatologically CRWB occurs to the north of the EDJ, predominantly within the northwest Atlantic region. Figure 3 shows that warm and cold CRWB significantly raises UK $\left[\mathrm{PM}_{10}\right]$, predominantly in the northwest Atlantic-European region and not in the northwest Atlantic region. Figure 3b shows that warm ACRWB is the most influential RWB sub-category in terms 
MSLP anomaly associated with anticyclonic RWB with $\log ([\mathrm{PM10}])>3.39$

(a)

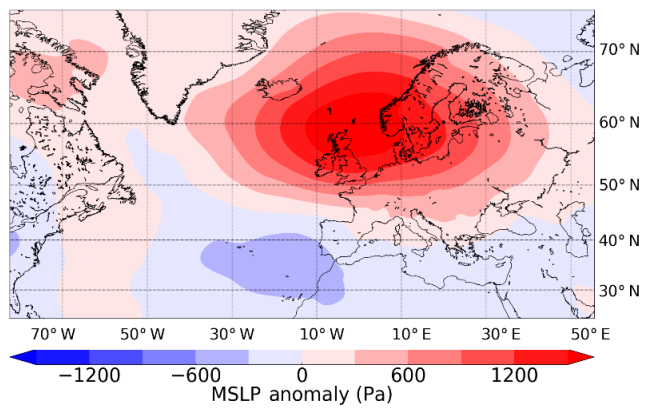

(c)

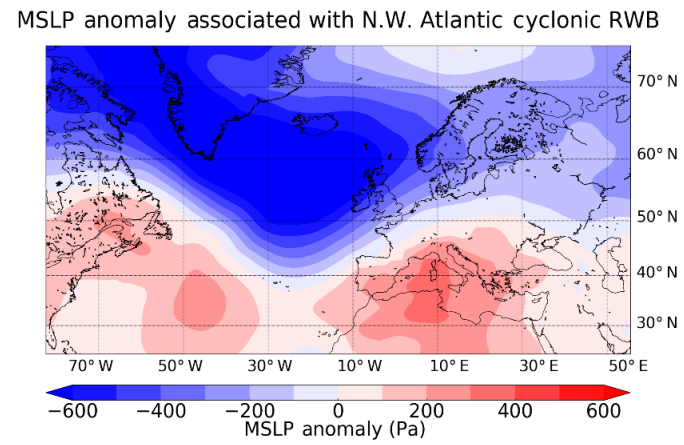

(b)

MSLP anomaly associated with cyclonic RWB with $\log ([\mathrm{PM} 10])>3.39$

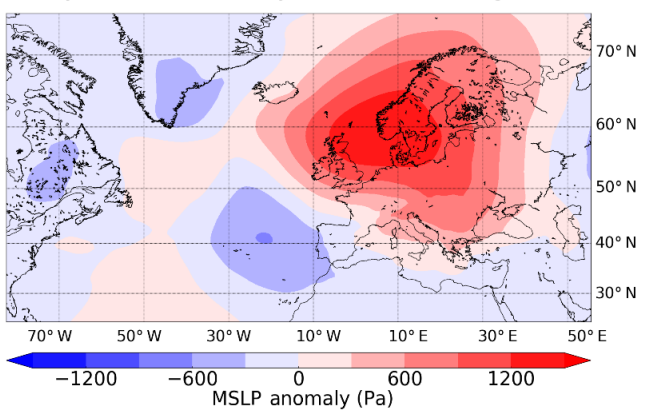

MSLP anomaly associated with N.E. Atlantic/European cyclonic RWB

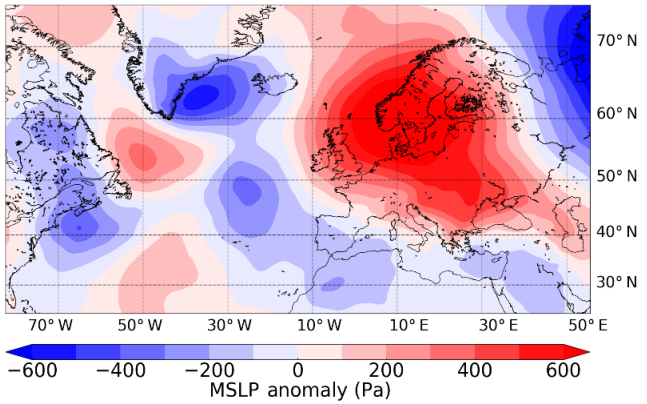

Figure 4. (a) and (b) Composite MSLP anomaly on the day following days incorporating anticyclonic RWB and cyclonic RWB within the regions of predefined influence (see Fig. 3) respectively, and on the day following RWB, $\ln \left[\mathrm{PM}_{10}\right]>3.39$. (c) and (d) MSLP anomaly on the day following days incorporating cyclonic RWB within the regions of predefined influence in the northwest Atlantic and northeast Atlantic-European sectors respectively, regardless of $\left[\mathrm{PM}_{10}\right]$. Pressure data were taken for the winter months (DJF) between January 1999 and December 2008.

of its regional extent, although warm CRWB exhibits the largest mean $\ln \left[\mathrm{PM}_{10}\right]$ magnitudes. The results from Fig. 3 support Fig. 1, as they illustrate the influence of RWB on UK $\left[\mathrm{PM}_{10}\right]$, predominantly within the same region as the positive correlation in Fig. 1. Following Fig. 3, all RWB subcategories are analysed for events occurring within their solid contoured significant regions.

\subsection{Pressure composites associated with RWB-driven UK $\left[\mathrm{PM}_{10}\right]$ exceedances}

M12 and M13 illustrated the climatological pressure response to each of the four RWB subsets in Table 1. M12 show that, climatologically, CRWB exhibits a pressure dipole over west Greenland, while ACRWB results in the same dipole centred over western Europe. Figure 4 illustrates composite MSLP anomalies 1 day after days incorporating (a) ACRWB and (b) CRWB events within their regions of influence and that lead to a UK $\left[\mathrm{PM}_{10}\right]$ exceedance $\left(\ln \left[\mathrm{PM}_{10}\right]>3.39\right)$ the following day.

In Fig. 3 for any given day, the $\mathrm{PM}_{10}$ value of that day may be placed into two or more RWB subsets, but for this analysis only one RWB subset is elected per day based on the following criteria. Firstly the greatest BI value is found in each region of influence. This BI value must correspond to the RWB subset of the region of influence within which it was found, based on the corresponding DB and RI indices for that grid point (e.g. warm ACRWB). An occurrence threshold of 10 positive BI values, with the same DB and RI metric classifications, has been applied within the region of influence. These criteria have been applied so that the largest RWB events (greatest BI values) must occur within the region of influential RWB for that subset. Furthermore the 10-event threshold imposes a spatial robustness for that specific RWB subset. If more than one RWB subset has occurred within its region of influence, then the RWB subset occurring with the greatest magnitude of overturning (BI value) is selected as the dominant RWB type for that day. This ensures that only one RWB subset can be selected as the most influential RWB subset on any given day.

Figure $4 \mathrm{a}$ and $\mathrm{b}$ are constructed using the combined warm and cold ACRWB and CRWB subsets listed in Table 1 and are composed of 50 and 35 contributing days respectively. The figures are similar, with a dominant high MSLP anomaly situated over Scandinavia and a low MSLP anomaly over the Azores. Together the high- and low-pressure anomalies complete the anomalous MSLP dipole expected of RWB. In both cases the anomalous MSLP dipole is centred over northern France, indicating that the RWB generating this dipole occurred, on average, in this region. 
(a)

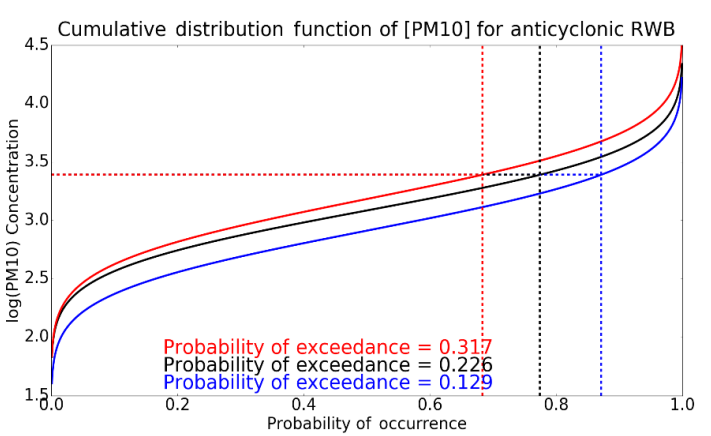

(c)

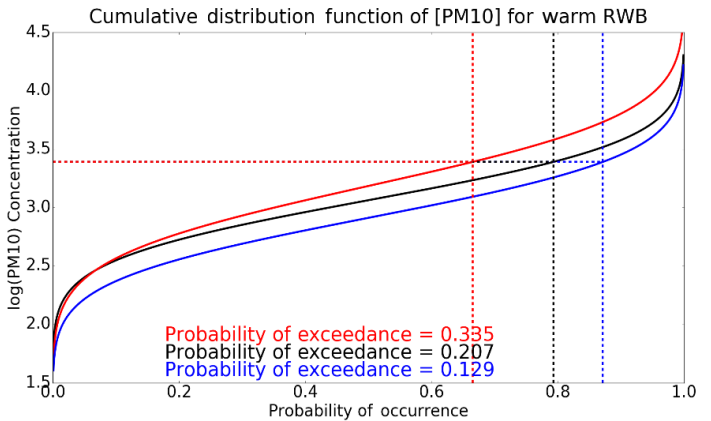

(b)

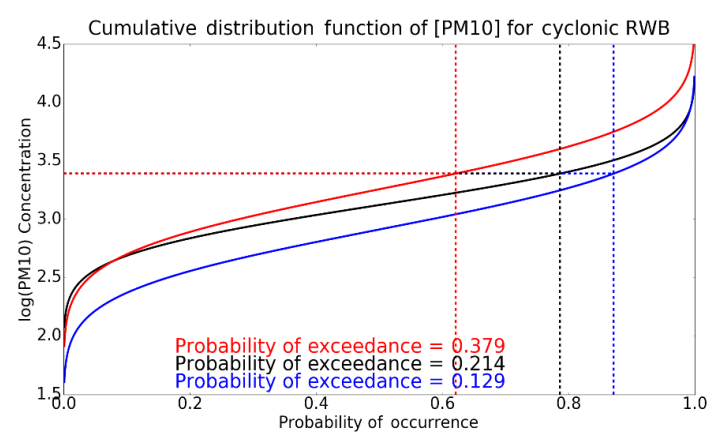

(d)

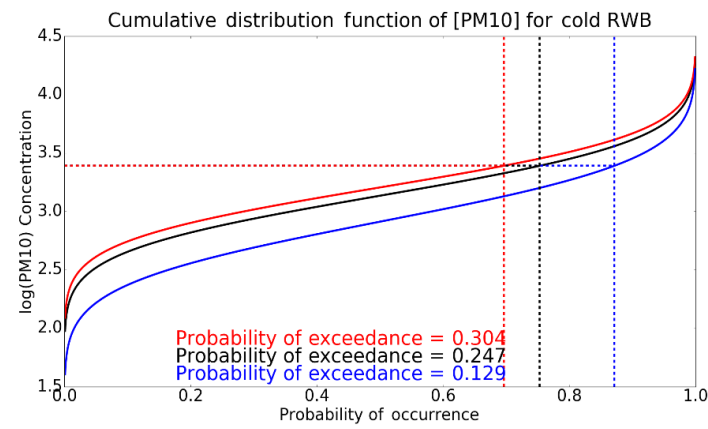

Figure 5. Cumulative distribution functions (CDFs) for UK $\ln \left[\mathrm{PM}_{10}\right]$ and (a) anticyclonic, (b) cyclonic, (c) warm and (d) cold RWB. The red line illustrates the CDF for each RWB subset following a day with RWB of any type within the respective region of influence (continuous event). The black line illustrates the CDF for each RWB subset following a day with no RWB of any type (onset event), and the blue represents $\left[\mathrm{PM}_{10}\right]$ associated with no RWB. Data were obtained for DJF January 1999-December 2008, and [PM 10 is lagged by 1 day following detection of RWB. Values shown for probability of exceedance are calculated as $1 \alpha$, where $\alpha$ is the probability of occurrence.

Figure $4 \mathrm{c}$ and d illustrate the composite MSLP anomaly 1 day after all CRWB occurrence (regardless of $\left[\mathrm{PM}_{10}\right]$ ) inside the regions of influence, within the northwest Atlantic and northeast Atlantic-European sectors respectively. The decision to dissect CRWB occurrence into two sectors follows the result that the regions of influence for CRWB have a greater regional extent in the northeast Atlantic-European sector than in the northwest Atlantic sector (Fig. 3c and d). In contrast it has been highlighted in the literature that CRWB is most likely to occur in the northwest Atlantic sector and to the north of the EDJ. The purpose of Fig. $4 \mathrm{c}$ and $\mathrm{d}$ is to determine the region in which CRWB occurrence is most likely to lead to $\left[\mathrm{PM}_{10}\right]$ exceedances. The longitudinal sectors incorporating these two regions were $225-329^{\circ} \mathrm{E}$ longitude for northwest Atlantic RWB and 330-55.5 ${ }^{\circ} \mathrm{E}$ longitude for northeast Atlantic-European RWB.

The number of events in Fig. $4 c$ and d is 52 and 22 in the northwest Atlantic and northeast Atlantic-European sectors respectively. The greater number of events in Fig. $4 \mathrm{c}$ than d, despite the much smaller regions of influence in the northwest Atlantic sector than the northeast Atlantic-European sector (Fig. 3c and d), highlights the greater density of CRWB events in the northwest Atlantic region.

Both Fig. $4 \mathrm{~b}$ and d show similar anomalous MSLP patterns, with an anomalously high MSLP system centred over the west Scandinavia region. This suggests that CRWB events leading to UK $\left[\mathrm{PM}_{10}\right]$ exceedances in Fig. $4 \mathrm{~b}$ are predominantly northeast Atlantic-European CRWB events. Figure $4 \mathrm{c}$, however, shows a negative MSLP anomaly stretched across the North Atlantic towards the UK. This pattern would suggest that northwest Atlantic CRWB events coincide with conditions favourable for UK $\left[\mathrm{PM}_{10}\right]$ dispersion and removal.

\subsection{Importance of RWB upon UK [PM 10$]$ exceedances}

In this section we focus on the RWB events leading to UK $\left[\mathrm{PM}_{10}\right]$ exceedances. Section 3.1 highlighted that raised UK $\left[\mathrm{PM}_{10}\right]$ is associated with positive $\mathrm{BI}$ values, showing that RWB has an effect of preventing the strongest westerly zonal winds from entering the UK region. Figure 3 shows the importance of RWB in significantly raising $\mathrm{UK} \overline{\left[\mathrm{PM}_{10}\right]}$ but does not demonstrate the probability of individual RWB events exceeding a $\ln \left[\mathrm{PM}_{10}\right]$ threshold of 3.39 .

Determining the probability of $\mathrm{PM}_{10}$ exceedance values is perhaps the most important result within this study, as it quantifies the importance of RWB on $\left[\mathrm{PM}_{10}\right]$ levels detrimental for human health. As explained in Sect. 2.4 the exceedance value this study uses is $29.72 \mu \mathrm{g} \mathrm{m}^{-3}$ $\left(\ln \left[\mathrm{PM}_{10}\right]=3.39\right)$.

To illustrate the probability of exceeding a UK Midlands $\left[\mathrm{PM}_{10}\right]$ threshold, Fig. 5 illustrates four cumulative distribu- 
tion function (CDF) plots. The CDFs in Fig. 5 present the probability of exceeding any $\ln \left[\mathrm{PM}_{10}\right]$ value, for three subset $\left[\mathrm{PM}_{10}\right]$ datasets. The first dataset (blue in Fig. 5) relates to days where no RWB of any type was detected within the region of RWB influence for that RWB subset. The black line in Fig. 5 represents days where RWB of the subset being analysed has occurred, following a day of no RWB (defined as onset RWB events). The red line represents continuous RWB events where RWB of the subset being analysed has followed a day of RWB of any type.

M13, Woollings et al. (2008) and Pelly and Hoskins (2003) recognised the importance of the persistence of atmospheric blocking in influencing synoptic meteorology. As yet, this study has not imposed any persistence criteria on the RWB metrics used. RWB persistence is expected to prolong the influence of atmospheric blocking and the resultant meteorological patterns. In the context of this study, it is expected that persistent events would be associated with the most hazardous UK $\left[\mathrm{PM}_{10}\right]$ events.

As for Fig. 4, each day can only be associated with a single RWB subset, which has occurred with the greatest BI magnitude within its region of influence. Furthermore, as in Fig. 4, a threshold of 10 grid points has been used to determine RWB occurrence. Finally, following the finding in Fig. 4 that northwest Atlantic CRWB has a detrimental influence on meteorology leading to $\mathrm{PM}_{10}$ accumulation, only RWB within the longitudinal bounds of $330-55.5^{\circ} \mathrm{E}$ is included in the analysis.

RWB has been analysed in four subcategories: warm, cold, anticyclonic and cyclonic. Values for probability of exceedance are shown in each figure and are calculated as 1- $\alpha$, where $\alpha$ is the probability of occurrence shown in Fig. 5. The probability of exceedance associated with no RWB is 0.129 , and all RWB events can be seen to exceed this probability in Fig. 5. From onset (RWB within a region of influence following a day of no RWB within a region of influence) it can be seen that the probability of exceedance is greatest for cold RWB (0.247) and lowest for warm RWB (0.207). The greatest probabilities can be seen for continuation events (RWB within a region of influence following a day of any RWB subset within its region of influence). Unlike for onset events, the probability of exceedance for CRWB events (0.379) is greater than that of ACRWB (0.317), with continuous CRWB events representing the greatest exceedance probability in Fig. 5. It is an unexpected result that CRWB, whose climatologically most frequent location is situated in the northwest Atlantic region, has greater influence upon UK $\left[\mathrm{PM}_{10}\right]$ than ACRWB, which is most frequent within the northeast Atlantic-European sector.

Section 3.3 showed that CRWB is most influential when it occurs within the northeast Atlantic-European sector, a region separated from its climatologically most frequent region. Furthermore it was shown that the anomalous MSLP pattern for influential CRWB bears great resemblance to influential ACRWB (Fig. 4a and b) and is within a similar re- gion of influence (Fig. 3). Section 3.4 quantified the probability of exceedance for CRWB and showed that it has a greater UK $\left[\mathrm{PM}_{10}\right]$ exceedance probability as a continuous event than ACRWB. Therefore it is hypothesised that, if CRWB is to become influential upon $\mathrm{UK} \mathrm{PM}_{10}$, it must be preceded by ACRWB within the northeast Atlantic-European region.

\subsection{Influential CRWB hypothesis}

The mechanism primarily dictating the direction of RWB is the meridional shear of the zonal wind, determined by the relative position of the EDJ. To the north (south) of the EDJ, a cyclonic (anticyclonic) shear is present. Consequently, the region of most frequent $\mathrm{CRWB}$ has been found to occur to the north of the EDJ mean state, in the northwest Atlantic region (Weijenborg et al., 2012). These regions are similar to those for ACRWB and predominantly to the south of the EDJ mean state. A hypothesis has been developed to explain the importance of CRWB in the northeast Atlantic-European region. It will be shown that the majority of northeast AtlanticEuropean CRWB events, which were found to significantly increase $\mathrm{UK} \mathrm{PM}_{10}$ ], are dependent on the prior occurrence of ARCWB.

Figure 6 shows a schematic which illustrates how CRWB can become influential following an ACRWB event. Figure 6 a shows the mature stage of an ACRWB event in which the mid-latitude EDJ is displaced to the south of the resultant high-pressure lobe. Subsequently with a more southerly EDJ, colder poleward air is advected into the positive potential vorticity anomaly, such as in Fig. 6 b, forming an $\Omega$ block. Following the generation of an $\Omega$ block, a cut-off - formed of anomalously negative potential vorticity, warm, equatorward air - may form as in Fig. 6c. In Fig. 6, red shading represents regions of detected ACRWB, while CRWB is represented by blue shading. West (upstream) of the ACRWB event seen in Fig. 6b, a CRWB event is detected, which is consistent with the regions of influence seen in Fig. 3c and d. It is hypothesised that CRWB occurs upstream of the ACRWB due to meridional zonal velocity shear determined by the relatively southerly position of the EDJ approaching the blocking dipole. Subsequently cyclonic vorticity is imparted on the background flow to the north of the EDJ approaching the blocking dipole, and CRWB can occur.

\subsubsection{Dependence of northeast Atlantic-European CRWB upon the prior occurrence of ACRWB}

In Fig. 6, CRWB occurrence within the northeast AtlanticEuropean influential region follows prior ACRWB occurrence in the region. Further analysis has shown that this is the case in $94 \%$ of northeast Atlantic-European CRWB events observed throughout January 1999-December 2008. Thirtyfive individual CRWB events were detected throughout the sampling period, using the 10-grid-point threshold used for identifying RWB events in Fig. 4. The 10-grid-point thresh- 


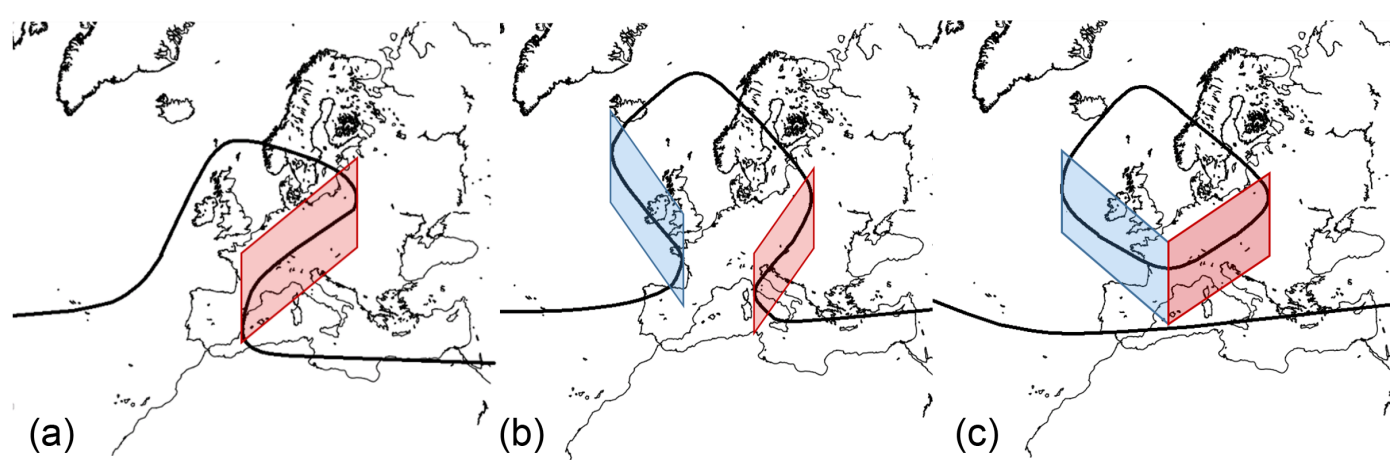

Figure 6. (a) Schematic of a mature warm-anticyclonic Rossby wave breaking event on the dynamical tropopause, with a region of positive BI and anticyclonic DB index values shaded red. The black contour portrays an arbitrary potential temperature contour representing the intermediate between anomalously cold and warm air masses. (b) Schematic of an $\Omega$ block with an additional cold-cyclonic Rossby wave breaking event (blue) following (a). (c) Schematic of a final stage warm $\theta$ cut-off.

Mean cyclonic and anticyclonic RWB occurrences throughout omega cyclonic RWB events

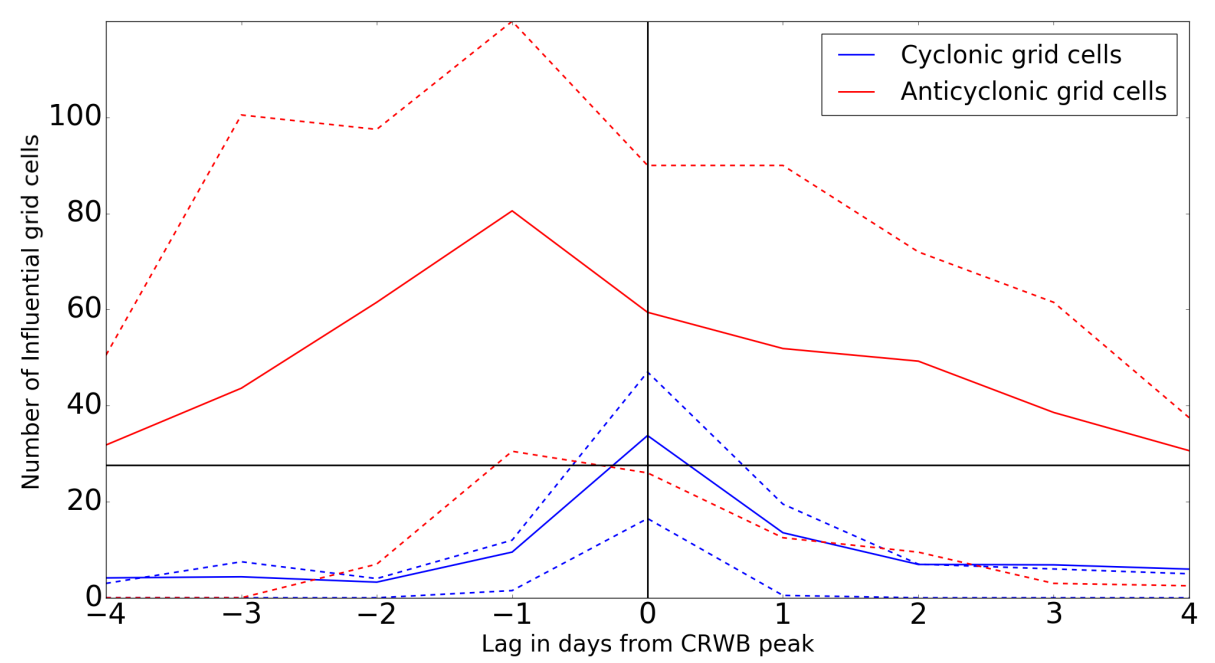

Figure 7. Grid points displaying RWB of (anti)cyclonic tendency in (red) blue with time in days relative to the peak of northeast AtlanticEuropean CRWB events. Solid lines represent the mean grid point count, while the dashed lines represent the 25th and 75 th percentile of counts for all events. In the formation of an $\Omega$ block an ACRWB precursor is required. Of the 35 CRWB events detected within the northeast Atlantic-European sector throughout January 1999-December 2008, 33 fulfilled the criteria of prior ACRWB occurrence. All CRWB events displayed in Fig. 7 include an ACRWB precursor within the 4 days leading up to and including the CRWB event. The black horizontal line represents the mean ACRWB count (30.07 grid points) throughout the dataset.

old helped to remove some smaller transient features. Unlike for Sect. 3.3 and 3.4 no criteria were imposed on the DB and RI metrics of the grid point with greatest BI value. In this section, it is less important to distinguish days influenced more by ACRWB and CRWB events, as Fig. 6 shows that both are influential in the formation of an $\Omega$ block. An ACRWB precursor was detected using the same 10-grid-point threshold within ACRWB regions of influence for the 4 days leading up to and including the day of CRWB occurrence. This indicated that prior ACRWB was likely to be related to the occurrence of CRWB within this region.

Figure 7 shows the mean count of ACRWB (solid red line) and CRWB (solid blue line) grid points, on the days sur- rounding a CRWB event. Every event is centred on its peak CRWB grid point count, and for each day a 25th and 75th percentile have been included (dashed lines) to test whether the data have been skewed by outliers.

Figure 7 shows the CRWB and ACRWB counts for $94 \%$ of northeast Atlantic-European CRWB events as defined within this study. Evident is the influence ACRWB plays upon the occurrence of CRWB, with the mean ACRWB count being greater than the climatological average ACRWB count (black line) for the entire period of the CRWB event. The mean ACRWB count peaks 1 day prior to the CRWB event, with the 25th percentile for this period also exceeding the mean ACRWB count for the dataset (27.66 grid points). 
With the ACRWB 25th percentile above the black line in Fig. 7 for day -1 , this indicated that the ACRWB precursor is a robust feature for at least $75 \%$ of the northeast AtlanticEuropean CRWB events.

None of the northeast Atlantic-European CRWB events not associated with an ACRWB precursor led to a [PM $\left.\mathrm{PM}_{10}\right]$ exceedance on the day following northeast CRWB detection. For the dataset used to generate Fig. 7, the probability of exceedance is 0.383 , which is the greatest value found within this study. UK $\log _{e} \overline{\left.\mathrm{PM}_{10}\right]} \pm \sigma$ lagged by 1 day following day 0 of all CRWB events contributing to Fig. 7 is $3.29 \pm 0.35$. The climatological UK $\log _{e} \overline{\left[\mathrm{PM}_{10}\right]} \pm \sigma$ is $2.98 \pm 0.43$, and subsequently the $\overline{\left[\mathrm{PM}_{10}\right]}$ for the dataset contributing to Fig. 7 is significantly greater to the 99.9 th percentile $\left(p=6.64 \times 10^{-5}\right)$, using the ANOVA statistical test.

\section{Discussion}

\subsection{Do large-scale flow patterns influence UK $\left[\mathrm{PM}_{10}\right]$ ?}

The relationship between RWB and UK [PM $\left.\mathrm{PM}_{10}\right]$ has been shown to be one that is dominated by negative BI values (Fig. 1 and 2). Negative BI values represent zonal flow, which provides the most efficient UK PM 10 sinks (McGregor and Bamzelis, 1999). Associated with the strongest zonal flow over the UK is the presence of the EDJ. At times of atmospheric blocking, resulting from RWB over the northeast Atlantic-European sector, the EDJ is deflected to the north and/or south of the blocked region (Shutts, 1983), resulting in elevated UK [PM $\left.{ }_{10}\right]$ (Fig. 2). The correlation tri-pole in Fig. 1 consisting of positive correlation centred over the English Channel and two negative correlations to the north and south shows a signature of EDJ deflection. The two regions of negative correlation represent regions where the EDJ is deflected to during periods of blocked flow over the UK and subsequent raised UK $\left[\mathrm{PM}_{10}\right]$.

The use of RWB as the meteorological diagnostic in this paper differs from classical meteorological diagnostics often used, such as MSLP, wind speed and temperature (McGregor and Bamzelis, 1999; Buchholz et al., 2010; Eder et al., 1994). Justification for the use of the RWB metrics used in this paper can be sought from Woollings et al. (2008). Woollings et al. (2008) showed that RWB can account for the synoptic meteorological variability influencing the UK. The synoptic meteorological variability influencing the UK can be defined simplistically as zonal flow from the Atlantic influencing the UK or the UK being blocked from this flow. Furthermore RWB contains information relating to the spatial synoptic flow patterns and temporal variability. Temporal variability can be inferred from the upper-level field, and, such as in the case of the $\Omega$ block in this study, RWB metrics can tell us about the persistence of such blocked events.

\subsection{What large-scale flow patterns lead to raised UK $\overline{\left[\mathbf{P M}_{10}\right]}$ ?}

In this study, RWB was shown to significantly $(p<0.01)$ increase UK $\left[\mathrm{PM}_{10}\right]$, predominantly when it occurred in the northeast Atlantic-European region. Weijenborg et al. (2012) showed that ACRWB is most prominent within this region, and this study has also shown that ACRWB in this region significantly increases UK $\left[\mathrm{PM}_{10}\right]$. Weijenborg et al. (2012) and M13 both highlighted that CRWB is most prominent in the northwest Atlantic region. M13 highlighted that the dominant effect of North Atlantic CRWB is through the generation of a northwest Atlantic pressure dipole. This pressure dipole acts to flatten the North Atlantic EDJ and subsequently displace the EDJ to the south of the UK, reminiscent of the negative phase of the North Atlantic Oscillation. Following M13 showing that North Atlantic CRWB predominantly influences the UK through the removal of the EDJ from the UK, it was expected that CRWB would positively influence UK $\left[\mathrm{PM}_{10}\right]$ through this mechanism. Furthermore, in Sect. 3.1, it was shown that the dominant mechanism controlling UK $\left[\mathrm{PM}_{10}\right]$ is the EDJ, which supports the theory that a removal of the EDJ from the UK would influence increased $\left[\mathrm{PM}_{10}\right]$. However, rather than northwest Atlantic CRWB, Sect. 3.2 illustrated that it is predominantly northeast Atlantic-European CRWB occurring in a climatologically less frequent location that significantly raises UK $\left[\mathrm{PM}_{10}\right]$.

Section 3.3 showed that both CRWB and ACRWB occurring in their northeast Atlantic-European regions of influence and leading to $\left[\mathrm{PM}_{10}\right]$ exceedances $\left(>29.72 \mu \mathrm{g} \mathrm{m}^{-3}\right.$ ) the following day shared nearly identical MSLP responses. This result suggests that ACRWB and CRWB events were influencing the UK through the same mechanisms and that they are similar events. This opposes M13, who showed that the most dominant mechanisms influencing UK meteorology for CRWB and ACRWB were different. As mentioned above, M13 showed that CRWB is influential on western Europe synoptic meteorology through the formation of a northwest Atlantic pressure dipole that acts to flatten the EDJ across the North Atlantic. ACRWB however was shown to lead to a pressure dipole in the northeast Atlantic-European region that blocked western Europe from the EDJ. The MSLP response to northwest Atlantic CRWB in Fig. 4c, occurring in its regions of influence, showed a pattern contrasting to M13. This MSLP composite shows a negative MSLP anomaly stretching across the North Atlantic over the UK, which would indicate stronger $\mathrm{PM}_{10}$ removal processes such as precipitation and stronger wind speeds (McGregor and Bamzelis, 1999). Figure 4d showed that CRWB occurring in the northeast Atlantic-European region bore more resemblance to the MSLP pattern in Fig. 4a of CRWB leading to a $\left[\mathrm{PM}_{10}\right]$ exceedance 1 day later. Consequently, the results from Fig. 4 do not support the findings of M13 that CRWB is most influential on the UK when it occurs in the northwest 
Atlantic region. Alternatively, as for Fig. 3, Fig. 4 finds that CRWB leads to increased UK $\left[\mathrm{PM}_{10}\right]$ when it occurs in the northeast Atlantic region.

Previous literature has looked at the influence of synopticscale meteorology on UK $\left[\mathrm{PM}_{10}\right]$, with high- and lowfrequency meteorological variability explaining some of the variability present in UK $\left[\mathrm{PM}_{10}\right]$ datasets. Both $\mathrm{McGregor}$ and Bamzelis (1999) and Buchholz et al. (2010) used clustering techniques to identify low-frequency weather regimes that were influential on UK $\left[\mathrm{PM}_{10}\right]$. The primary conclusion was one that identified European anticyclonic regimes as the most influential to raised UK $\left[\mathrm{PM}_{10}\right]$, while maritime Atlantic air masses were conducive to low UK $\left[\mathrm{PM}_{10}\right]$. The results in this paper support these findings, as we point to the dominant anomalous MSLP response to RWB that leads to elevated $\mathrm{PM}_{10}$, being an anticyclone over Scandinavia. In the method we used, each day can be classified by a number of continuous metrics, as opposed to clustering techniques, which use discrete data in the form of regimes to classify each day. The advantage of this method is that no day can get misrepresented by using only a discrete number of clustered regimes. For example, rare yet very important events such as $\Omega$ block events are likely to be indistinguishable in a clustering framework.

\subsection{What large-scale flow patterns lead to the greatest probability of exceeding hazardous UK [PM $\left.\mathbf{P M}_{10}\right]$ limits?}

Katsouyanni et al. (2001) showed that episodic short-term exposure of $\left[\mathrm{PM}_{10}\right]>\overline{\left[\mathrm{PM}_{10}\right]}+10 \mu \mathrm{g} \mathrm{m}^{-3}$ led to a significant $(p<0.05)$ increase in urban mortality rates. Exceedance probability analysis focuses on episodic events above a hazardous $\left[\mathrm{PM}_{10}\right]$ threshold, determined following Katsouyanni et al. (2001). The probability of exceeding the study's hazardous UK Midlands [ $\mathrm{PM}_{10}$ ] threshold, associated with days where no RWB has occurred within a region of influence, is 0.129 . The occurrence of all RWB subsets led to an increase in this probability. In this study, the $\Omega$ block mechanism resulted in the greatest probability of exceeding a hazardous $\left[\mathrm{PM}_{10}\right]$ threshold (probability $=0.383$ ). The results in this paper suggest that such events are associated with two dominant mechanisms in raising $\mathrm{UK}\left[\mathrm{PM}_{10}\right]$. The first of these is associated with the advection of European $\mathrm{PM}_{10}$, consequently raising the UK background $\left[\mathrm{PM}_{10}\right]$. The ACRWB shown to precede the $\Omega$ blocking in Fig. 7 is associated with a Scandinavian high-pressure system and easterly advection into the UK, which is thought to facilitate the advection of European $\mathrm{PM}_{10}$ into the UK. Following this advection, CRWB occurring upstream of the preceding ACRWB event facilitates a persistence of conditions conducive to $\mathrm{PM}_{10}$ accumulation in the UK. This suggests that the occurrence of advection followed by the persistence of UK stagnation leads to the greatest $\mathrm{PM}_{10}$ exceedance probabilities in this study and consequently the most hazardous $\left[\mathrm{PM}_{10}\right]$ within the UK. This result will be the subject of future publication, which will help determine the dominant mechanisms by which RWB leads to UK $\mathrm{PM}_{10}$ exceedances.

The increased probability of exceedance associated with continuous events for most RWB subsets, as compared to onset events (Sect. 3.4), highlights the importance of RWB persistence in generating conditions conducive to hazardous UK $\left[\mathrm{PM}_{10}\right]$. Shutts (1983) detailed a mechanism by which a blocking dipole can be reinforced by eddies propagating from the EDJ circumnavigating the block. The blocking dipole will selectively absorb eddies with positive/negative PV anomalies in its low/high-pressure lobes. This PV reinforcement subsequently allows the block to persist and for conditions conducive to $\mathrm{PM}_{10}$ accumulation in the $\mathrm{UK}$ to also persist. Through the $\Omega$ block mechanism theorised in Fig. 6, it is suggested that eddy absorption allows the blocking dipole to persist as the EDJ circumnavigates the blocking dipole to the north.

The analysis of synoptic weather patterns suggests that the advection of European $\mathrm{PM}_{10}$ heavily contributes to the measured $\left[\mathrm{PM}_{10}\right]$ at the UK Midlands tri-site. Despite this, no source attribution study was undertaken throughout this analysis, and consequently no quantitative evaluation of the contribution of advected $\mathrm{PM}_{10}$ has been made. A potential follow-up study would be to quantitatively analyse the contribution of advected European $\mathrm{PM}_{10}$ in such RWB events, thereby attributing the sources contributing to hazardous UK $\mathrm{PM}_{10}$ events. Furthermore as RWB has been shown to increase the probability of exceeding a hazardous $\mathrm{PM}_{10}$ threshold limit, the changes in RWB frequency and potency must be understood through climate predictions. Climate predictions alongside quantitative $\mathrm{PM}_{10}$ source attribution studies and this work highlighting the hazard associated with RWB events will allow for mitigation measures to be implemented in sufficient time to alleviate the potential hazard $\mathrm{PM}_{10}$ poses to the UK population, through the mechanisms described in this paper.

In this study, $\mathrm{PM}_{10}$ advection from Europe is hypothesised to greatly influence UK $\left[\mathrm{PM}_{10}\right]$ episodes. A potential extension for this study could be to analyse the relationship between the smaller $\mathrm{PM}_{2.5}$ and RWB. $\mathrm{PM}_{2.5}$ is a smaller and thus lighter particle than $\mathrm{PM}_{10}$, with a reduced gravitational settling velocity. Consequently, $\mathrm{PM}_{2.5}$ is more readily advected than $\mathrm{PM}_{10}$, and RWB may therefore be more influential in facilitating the advection of $\mathrm{PM}_{2.5}$.

\section{Limitations and variability}

\subsection{Relating pressure and $\theta-2$ PVU fields}

This analysis looks at large-scale dynamical features affecting regional-scale UK $\left[\mathrm{PM}_{10}\right]$, and in this relationship there is an unconstrained intermediate. This intermediate is the pressure dipole response to RWB, which is not consistent in proximity with the centre of overturning (maximum BI 
value) in a RWB event. Previous studies have shown the anomalous high-pressure lobe to be located to the north of the RWB event, also found within this study. Despite latitudinal consistency, longitudinal differences in the distance between the centre of overturning and the local high-pressure maxima exist. Consequently variability exists within the results in Fig. 3, as UK $\left[\mathrm{PM}_{10}\right]$ is not solely dependent upon the location of overturning. The relationship between location of BI maxima and high-pressure maximum remains unconstrained, and therefore inherent uncertainty of this relationship exists.

\subsection{Observational tri-site}

The observational sites used within this study are all classified as urban background sites; therefore they will be influenced by their urban environments independently. Consequently there will be periods in the data that local influences outweigh the effects of large-scale episodes. Furthermore the tri-site is used to represent the UK from its most central point; in doing this, it is likely that some events, particularly some continental advection events affecting the southeast corner of the UK, will not be recorded. The extent to which three sites can represent the entire country is limited, but due to data availability it is not possible to fully represent the entirety of the UK without large-scale data interpolation methods, which are heavily influenced by the local influences of all sites used. The analysis within this paper has been repeated using data from a rural site at both Harwell, Oxfordshire, and Southampton, Hampshire.

The data from Southampton showed regions of influence with reduced magnitudes of extent for all RWB subsets, but especially for the two ACRWB subsets. It is hypothesised that ACRWB facilitates the advection of European $\mathrm{PM}_{10}$, driven by a Scandinavian anticyclone. Subsequently, in Southampton, where European pollution sources more regularly have a greater influence (Malcolm et al., 2000) than in the UK Midlands, the advection of European $\mathrm{PM}_{10}$ is not associated with as great a $\left[\mathrm{PM}_{10}\right]$ increase. Despite the reduced magnitudes, the regions of influence were spatially co-located with those illustrated in Fig. 3. Conclusions gathered from the analysis of exceedance probabilities did not change greatly. The exceedance probability for all RWB was elevated above the exceedance probability with no RWB (0.169). Continuous CRWB events led to the greatest exceedance probability (0.659) of the RWB subsets in Fig. 5, which was much greater than the exceedance probability for continuous ACRWB (0.323). Analysis of $\Omega$ blocks showed that these events led to the second-greatest probability of exceedance in Southampton (0.604). However, as for the UK Midlands $\mathrm{PM}_{10}$ dataset, the probability of exceedance for $\Omega$ block events is similar to that for continuous CRWB events, as they comprise many of the same events. Despite this and due to the reduced ACRWB regions of influence, only 11 out of 17 northeast Atlantic CRWB events were associated with an ACRWB precursor.
Data from the rural monitoring site in Harwell showed little difference in the shape or locations of the regions of influence for all RWB subsets, when compared with the UK Midlands dataset. The probability of exceeding a hazardous $\left[\mathrm{PM}_{10}\right]$ threshold, associated with days where no RWB has occurred, was reduced (0.082) for the Harwell dataset. The $\left[\mathrm{PM}_{10}\right]$ exceedance probabilities in Harwell are reduced, because the $10 \mu \mathrm{g} \mathrm{m}^{-3}$ increment used to define an exceedance represented a much greater proportion of the sites' $\left[\mathrm{PM}_{10}\right]$. Continuous CRWB events led to the greatest exceedance probability (0.368) of the RWB subsets illustrated in Fig. 5 as before. As for the two urban background sites, $\Omega$ block events led to the greatest overall exceedance probabilities (0.381), where 30 / 33 northeast Atlantic-European CRWB events were identified as $\Omega$ block events.

\section{Conclusions}

The influence that Rossby wave breaking has on UK PM 10 concentration $\left(\left[\mathrm{PM}_{10}\right]\right)$ has been analysed, with significant relationships present. Positive correlations exist within the northeast Atlantic-European region, between UK $\left[\mathrm{PM}_{10}\right]$ and the blocking index, a metric used to diagnose RWB. Primarily, the UK experiences either zonal or blocked flow, with the latter attributable in winter months to RWB. Zonal flow is associated with the strongest $\mathrm{PM}_{10}$ loss mechanisms, and it is the removal of zonal flow from the UK that dominates the positive correlation between RWB and UK $\left[\mathrm{PM}_{10}\right]$. The strongest zonal flow speeds and consequently greatest $\mathrm{PM}_{10}$ loss mechanisms are associated with the eddy-driven jet. The EDJ has shown to be the dominant mechanism in the relationship between RWB and UK PM 10 .

Analysis was undertaken to determine whether RWB can aid in the accumulation of UK $\left[\mathrm{PM}_{10}\right]$ above background concentrations. Regions of influence highlighted that RWB occurring in the northeast Atlantic-European region resulted in a significant $(p<0.01)$ increase in UK $\left[\mathrm{PM}_{10}\right]$ above climatological levels. Anticyclonic RWB (ACRWB) was seen to significantly raise mean $\left[\mathrm{PM}_{10}\right]\left(\overline{\left[\mathrm{PM}_{10}\right]}\right)$ when it occurred in the northeast Atlantic-European region. Additionally cyclonic RWB significantly raised UK $\mathrm{PM}_{10}$ when it occurred in a similar region, despite being climatologically uncommon in this region, due to the anticyclonic nature of background flow on the equatorial side of the EDJ. The MSLP response to both CRWB and ACRWB, resulting in $\mathrm{PM}_{10}$ exceedances, is dominated by an anomalous anticyclone, centred over Scandinavia. This results in easterlies into the UK and the advection of European PM.

As RWB events are deviations from the synoptic climatological mean state, the probability of exceeding an episodic $\left[\mathrm{PM}_{10}\right]$ threshold value was used to evaluate the anthropogenic health hazard associated with $\mathrm{PM}_{10}$. All RWB subsets led to an increase in exceedance probability, above days where no RWB was detected, when they occur within con- 
strained regions of influence. The occurrence of CRWB led to the greatest exceedance probability of any RWB subset. This was an unexpected result, as ACRWB is climatologically more frequent in the northeast Atlantic-European region and consequently more influential on UK meteorology than CRWB.

A mechanism was hypothesised, explaining the occurrence of CRWB within a region separate from its climatological most frequent region. The mechanism depended on the prior occurrence of ACRWB within the northeast AtlanticEuropean region and was characterised by the formation of an $\Omega$ block. The persistence of these events led to the probability of exceedance in such cases, exceeding that of all other RWB subsets, with the added influence of UK stagnation influencing raised UK $\left[\mathrm{PM}_{10}\right]$. The mechanism by which these events influence UK $\left[\mathrm{PM}_{10}\right]$ is through the initial advection of European $\mathrm{PM}_{10}$ into the UK through ACRWB within the northeast Atlantic-European region. Subsequently, a prolonged period of stagnation allows the accumulation of local $\mathrm{PM}_{10}$ sources to increase UK [PM $\left.\mathrm{PM}_{10}\right]$ further. The occurrence of advection and the persistence of stagnation is hypothesised to lead to the greatest UK $\left[\mathrm{PM}_{10}\right]$.

Further analysis has been suggested to quantitatively evaluate the sources of $\mathrm{PM}_{10}$ throughout such events. Furthermore analysis must be undertaken regarding the frequency of such events in a changing climate. Once source regions and the frequency of $\mathrm{PM}_{10}$ exceedances resulting from RWB in a future climate are known, mitigation steps can be made (if required) to alleviate any potential increase in RWB frequency or potency in a changing climate, through local or continental emission strategies. Without a full understanding of the relationship between meteorology, hazardous pollutant events and climate responses, the opportunity to implement effective mitigation steps now may be lost.

\section{Data availability}

$\mathrm{PM}_{10}$ data are available at https://uk-air.defra.gov.uk/data/ data_selector (DEFRA, 2014a) for all $\mathrm{PM}_{10}$ datasets used. ERA-Interim data are available from http://apps.ecmwf.int (Dee et al., 2011).

\section{The Supplement related to this article is available online at doi:10.5194/acp-17-867-2017-supplement.}

Competing interests. The authors declare that they have no conflict of interest.

Acknowledgement. Chris P. Webber was funded by a NERC PhD Studentship.
Edited by: P. Haynes

Reviewed by: three anonymous referees

\section{References}

Beelen, R., Raaschou-Nielsen, O., Stafoggia, M., Andersen, Z. J., Weinmayr, G., Hoffmann, B., Wolf, K., Samoli, E., Fischer, P., Nieuwenhuijsen, M., Vineis, P., Xun, W. W., Katsouyanni, K., Dimakopoulou, K., Oudin, A., Forsberg, B., Modig, L., Havulinna, A. S., Lanki, T., Turunen, A., Oftedal, B., Nystad, W., and Nafstad, P.: Effects of long-term exposure to air polution on natural-cause mortality: an analysis of 22 European cohorts within the multicentre ESCAPE project, Lancet, 383, 785-795, doi:10.1016/S0140-6736(13)62158-3, 2014.

Berrisford, P., Hoskins, B. J., and Tyrlis, E.: Blocking and Rossby wave breaking on the Dynamical Tropopause in the Southern Hemisphere, J. Atmos. Sci., 64, 2881-2898, doi:10.1175/JAS3984.1, 2007.

Brook, R. D., Rajagopalan, S., Pope, C. A. III, Brook, J. R., Bhatnagar, A., Diez-Roux, A. V., Holguin, F., Hong, Y., Luepker, R. V., Mittleman, M. A., and Peters, A.: Particulate matter air pollution and cardiovascular disease an update to the scientific statement from the American Heart Association, Circulation, 121, 23312378, 2010.

Buchholz, S., Junk, J., Krein, A., Heinemann, G., and Hoffmann, L.: Air pollution characteristics associated with mesoscale atmospheric patterns in northwest continental Europe, Atmos. Environ., 44, 5183-5190, doi:10.1016/j.atmosenv.2010.08.053, 2010.

Cattiaux, J., Vautard, R., Cassou, C., Yiou, P., Masson-Delmotte, V., and Codron, F.: Winter 2010 in Europe: a cold extreme in a warming climate, Geophys. Res. Lett., 37, 20, doi:10.1029/2010GL044613, 2010.

Charron, A., Degrendele, C., Laongsri, B., and Harrison, R. M.: Receptor modelling of secondary and carbonaceous particulate matter at a southern UK site, Atmos. Chem. Phys., 13, 1879-1894, doi:10.5194/acp-13-1879-2013, 2013.

Council of the European Union and Parliament of the European Union: Directive 2008/50/EC of the European Parliament and of the Council, 2008.

Dee, D. P., Uppala, S. M., Simmons, A. J., Berrisford, P., Poli, P., Kobayashi, S., Andrae, U., Balmaseda, M. A., Balsamo, G., Bauer, P., and Bechtold, P.: The ERA-Interim reanalysis: Configuration and performance of the data assimilation system, Q. J. Roy. Meteor. Soc., 137, 553-597, doi:10.1002/qj.828, 2011.

DEFRA: Department of Environment, Food and Rural Affairs, available at: https://uk-air.defra.gov.uk/data/data_selector/ (last access: October 2013), 2014a.

DEFRA: Department of Environment, Food and Rural Affairs, available at: https://uk-air.defra.gov.uk/ (last access: October 2013), 2014b.

Eder, B. K., Davis, J. M., and Bloomfield, P.: An automated classification scheme designed to better elucidate the dependence of ozone on meteorology, J. Appl. Meteorol., 33, 1182-1199, doi:10.1175/1520-0450(1994)033<1182:AACSDT>2.0.CO;2, 1994.

Gehring, U., Gruzieva, O., Agius, R. M., Beelen, R., Custovic, A., Cyrys, J., Eeftens, M., Flexeder, C., Fuertes, E., Heinrich, 
J., Hoffmann, B., de Jongste, J. C., Kerkhof, M., Klümper, C., Korek, M., Mölter, A., Schultz, E. S., Simpson, A., Sugiri, D., Svartengren, M., von Berg, A., Wijga, A. H., Pershagen, G., and Brunekreef B.: Air Pollution Exposure and Lung Function in Children: The ESCAPE Project, Children's Health Prespect, 121, 1357-1364, doi:10.1289/ehp.1306770, 2013.

Haynes, P. H.: CRITICAL LAYERS, in: Encyclopedia of Atmospheric Sciences, edited by: Holton, J. R., Academic Press, Oxford, UK, 582-589, doi:10.1016/B0-12-227090-8/00126-3, 2003.

Hoskins, B. J.: A potential vorticty view of synoptic development, Meteor. Appl., 4, 325-334, doi:10.1017/S1350482797000716, 1997.

Kappos, A. D., Bruckmann, P., Eikmann, T., Englert, N., Heinrich, U., Höppe, P., Koch, E., Krause, G. H. M., Kreyling, W. G., Rauchfuss, K., Rombout, P., Schulz-Klemp, V., R. Thiel, W., and Wichmann H-E.: Health effects of particles in ambient air, Int. J. Hyg. Envir. Heal., 207, 399-407, doi:10.1078/1438-4639-00306, 2004.

Katsouyanni, K., Touloumi, G., Samoli, E., Gryparis, A., Le Tertre, A., Monopolis, Y., Rossi, G., Zmirou, D., Ballester, F., Boumghar, A., Anderson, H. R., Wojtniak, B., Paldy, A., Braunstein, R., Pekkanen, J., Schindler, C., and Schwartz, J.: Confounding and effect modification in the short-term effects of ambient particles on total mortality: results from 29 European cities within the APHEA2 project, Epidemiology, 12, 521-531, 2001.

Malcolm, A. L., Derwent, R. G., and Maryon, R. H.: Modelling the long-range transport of secondary PM 10 to the UK. Atmos. Environ., 34, 881-894, doi:10.1016/S1352-2310(99)00352-0, 2000.

Masato, G., Hoskins, B. J., and Woollings, T.: Wave-breaking Characteristics of Midlatitude Blocking, Q. J. Roy. Meteor. Soc., 138, 1285-1296, doi:10.1002/qj.990, 2012.

Masato, G., Hoskins, B. J., and Woollings, T.: Wave-breaking Characteristics of Northern Hemisphere Winter Blocking: A Two-Dimensional Approach, J. Climate, 26, 4535-4549, doi:10.1175/JCLI-D-12-00240.1, 2013.
McGregor, G. R.: Chapter 3, Basic Meteorology, in: Air Pollution and Health, edited by: Holgate, S., Samet, J. M., Koren, H. S., and Maynard, R. L., Academic Press, London, UK, 21-49, 1999.

McGregor, G. R. and Bamzelis, D.: Synoptic typing and its application to the investigation of weather air pollution relationships, Birmingham, United Kingdom, Theor. Appl. Climatol., 51, 223 236, doi:10.1007/BF00867281, 1995.

Morgan, M. C. and Nielsen-Gammon, J. W.: Using tropopause maps to diagnose midlatitude weather systems, Mon. Weather Rev., 126, 2555-2579, doi:10.1175/15200493(1998)126<2555:UTMTDM>2.0.CO;2, 1998.

Pelly, J. L. and Hoskins, B. J.: A New Perspective on Blocking, J. Atmos. Sci, 50, 743-755, doi:10.1175/15200469(2003)060<0743:ANPOB>2.0.CO;2, 2003.

Pope, R. J., Savage, N. H., Chipperfield, M. P., Ordóñez, C., and Neal, L. S.: The influence of synoptic weather regimes on UK air quality: regional model studies of tropospheric column $\mathrm{NO}_{2}$, Atmos. Chem. Phys., 15, 11201-11215, doi:10.5194/acp-1511201-2015, 2015.

Shutts, G. J.: The propogation of eddies in diffluent jetstreams: eddy vorticity forcing of "blocking" flow fields, Q. J. Roy. Meteor. Soc., 109, 737-761, doi:10.1002/qj.49710946204, 1983.

Tyrlis, E. and Hoskins, B. J.: The Morphology of Northern Hemisphere Blocking, J. Atmos. Sci, 65, 1653-1665, doi:10.1175/2007JAS2338.1, 2008.

Weijenborg, C., de Vries, H., and Haarsma, R. J.: On the direction of Rossby wave breaking in blocking, Clim. Dynam., 39, 2823 2831, doi:10.1007/s00382-012-1332-1, 2012.

Woollings, T. J., Hoskins, B. J., Blackburn, M., and Berrisford, P.: A new Rossby wave-breaking interpretation of the North Atlantic Oscillation, J. Atmos. Sci, 65, 609-626, doi:10.1175/2007JAS2347.1, 2008.

Yin, J. and Harrison, M.: Pragmatic mass closure study for $\mathrm{PM}_{1} .0, \mathrm{PM}_{2.5}$ and $\mathrm{PM}_{10}$ at roadside, urban background and rural sites. Atmos. Environ., 42, 980-988, doi:10.1016/j.atmosenv.2007.10.005, 2008. 